\title{
Depressive Symptoms of Latinx Women in Rural Farmworker and Urban Non-Farmworker Families in North Carolina
}

\author{
Thomas A. Arcury ${ }^{1}$ (D) Sydney A. Smith ${ }^{2}$. Jennifer W. Talton ${ }^{2} \cdot$ Haiying Chen $^{2} \cdot$ Paul J. Laurienti $^{3} \cdot$ Sara A. Quandt ${ }^{4}$
}

Received: 27 August 2021 / Revised: 5 October 2021 / Accepted: 14 October 2021 / Published online: 25 October 2021

(c) W. Montague Cobb-NMA Health Institute 2021

\begin{abstract}
Background Mental health among low-income Latinx women in the United States (US), including those in farmworker families, is a health equity concern. This analysis (1) describes the depressive symptoms among Latinx women in rural farmworker families and urban non-farmworker families and (2) delineates immigration and acculturation, family composition and disruption, and financial characteristics associated with depressive symptoms experienced by these women.

Methods Data are from a 2019-2020 cross-sectional survey of 66 rural farmworker and 52 urban non-farmworker women with a child participating in a study of pesticide exposure and neurocognitive development. Depressive symptoms were measured with the CES-D Short Form.

Results The median (25th-75th percentiles) depressive symptom score reported was 2.0 (1.0-4.0), with 10 (8.5\%) women having depressive symptom scores of 10 or greater. In bivariate analysis, among immigration and acculturation characteristics, women born in the USA and who spoke English fluently had lower depressive symptom scores. Among family composition and disruption characteristics, married women, and those with two adults in the household had lower depressive symptom scores. No financial status characteristic had statistically significant associations with depressive symptom score. In multivariate analysis, rural farmworker women had an expected median score one point lower than did urban non-farmworker women. Conclusion Addressing mental health among immigrant women, particularly those in farmworker families, is a complex undertaking. Rural versus urban locality provides a context for mental health. Determining the proximal determinants of locality requires further analysis.
\end{abstract}

Keywords Women's health $\cdot$ Health equity $\cdot$ Mental health $\cdot$ Rural health $\cdot$ Occupational health

\section{Introduction}

The mental health of low-income and working class Latinx in the United States (US) is an ongoing health equity concern [1]. This concern is especially pertinent for Latinx

Thomas A. Arcury

tarcury@wakehealth.edu

1 Department of Family and Community Medicine, Wake Forest School of Medicine, Winston-Salem, NC, USA

2 Department of Biostatistics and Data Science, Division of Public Health Sciences, Wake Forest School of Medicine, Winston-Salem, NC, USA

3 Department of Radiology, Wake Forest School of Medicine, Winston-Salem, NC, USA

4 Department of Epidemiology and Prevention, Division of Public Health Sciences, Wake Forest School of Medicine, Winston-Salem, NC, USA farmworker family members who must deal with significant situational and structural stressors [2]. Situational stressors include family separation, family responsibility, social marginalization, poor housing conditions, poor work conditions and substantial work demands, and poor physical health [2]. An additional situational stressor for women in farmworker communities is sexual harassment and abuse [3-5]. Structural stressors include discrimination, acculturation, documentation status, poverty, and limited access to health care [2].

Latinx farmworker mental health research has examined a limited set of issues, including stress [6-8], anxiety [9, 10], and alcohol use disorder [11-13], as well as depression [7, 14-17]. The prevalence of elevated depressive symptoms reported for Latinx migrant and seasonal farmworkers is highly variable, ranging from $6 \%$ to $45 \%$ [2]. This variability results in part from differences in instruments and differences in definitions for identifying cases. Although 
women constitute one third of Latinx migrant and seasonal farmworkers and women not employed in agriculture are often present in farmworker families, little farmworker mental health research has specifically considered women farmworkers or women in farmworker families [2, 18]. This is particularly the case for depression and depressive symptoms.

Fortunately, analyses of depressive symptoms among women employed as farmworkers women and those in farmworker families (families in which at least one member is employed as a migrant or seasonal farmworker) have generally used the same measure of depressive symptoms, the short version of the Center for Epidemiological Studies-Depression Scale (CES-D) [19]. Scores for this ten-item scale can range from 0 to 30 , with a score of 10 or higher indicating elevated depressive symptoms. The one analysis of depressive symptoms among women employed as farmworkers found that their mean depressive symptom score was 6.1 (Standard Deviation (SD) 4.8) [12].

A set of analyses focused on Latinx women in farmworker families who had at least one child (about one third of whom were employed as farmworkers, about one third were not employed outside the home, and about one third were employed in other industries) found, depending on the inclusion criteria for the specific analysis, that they had a mean depressive symptoms score of 5.9 (SD 4.5) [19] to 7.2 (SD 5.6) [21]. Thirty-one percent of these women had a score of 10 or greater, indicating elevated depressive symptoms [21, 22]. Longitudinal analysis documenting depressive symptoms among Latinx women in farmworker families indicates that depressive symptoms are variable [23]; women did not experience elevated depressive symptom scores for about two thirds of eight points over a 2-year period, yet about two thirds of these women reported elevated depressive symptom scores at least once during this period.

These studies point to three sets of factors that should be considered in understanding depressive symptoms among women employed as farmworkers and women in farmworker families. The first set is immigration and acculturation. Being a migrant farmworker is associated with an increased risk for greater depressive symptoms among women employed as seasonal farmworkers [20]. The second set is family composition and disruption. Family disruption (measured with the item "we fight a lot in our family") is associated with greater depressive symptoms among Latinx women in farmworker families [21]. The third set is financial status. Similar to women in other studies [24, 25], financial problems, such as economic insecurity, are related to greater depressive symptoms among Latinx women in farmworker families [21, 22]. Specific occupation (farm work versus operative or domestic worker) is not associated with depressive symptoms among women in farmworker families $[12,20]$. However, several work organization characteristics, including nonstandard shift, psychological demand, and lack of skill variety, are marginally associated with increased depressive symptoms [20].

A few investigations compare the mental health of women in farmworker families to that of Latinx urban women. Analyses in North Carolina report that Latinx urban women have levels of depressive symptoms similar to those reported for women in farmworker families; for example, Latinx women working in poultry processing plants and those working in other manual jobs had a mean depressive symptom score of 6.2 based on the short version of the CES-D [26]. Direct comparison of Latinx women employed as farmworkers with Latinx women employed in other occupations and unemployed Latinx women not in farmworker families found that depressive symptoms, although high, did not differ significantly by occupation and employment [12. As with Latinx women employed as farmworkers [20], among Latinx women employed in non-agricultural manual jobs, such job characteristics as awkward position, skill variety, and psychological demands were associated with greater depressive symptoms [26].

This analysis uses data for low-income Latinx women in North Carolina with at least one child to addresses two aims. The first aim is to describe the level of depressive symptoms among Latinx women in rural farmworker families as compared to urban non-farmworker families. The second aim is to delineate the immigration and acculturation, family composition and disruption, and financial characteristics associated with depressive symptoms experienced by these women.

\section{Methods}

This analysis uses data collected as part of the Preventing Agricultural Pesticide Exposure 5 (PACE5) study, a community-based participatory research collaboration between Wake Forest School of Medicine and the North Carolina Farmworkers Project (Benson, NC; http://ncfwp.org/.). PACE5 is a large, two-group, prospective study examining the health and cognitive effects of pesticide exposure for Latinx children in farmworker and non-farmworker families. The study's comparative design includes a sample of children in rural, Latinx farmworker families and a sample of children in similar urban, Latinx families with no members employed as farmworkers. The Wake Forest School of Medicine Institutional Review Board approved the PACE5 study protocol, and the study received a Certificate of Confidentiality from the National Institutes of Health.

\section{Participants}

Participants in this analysis are the mothers of children recruited to the PACE5 study. Inclusion criteria for the 
children were age 8 years at baseline and completed the first grade in a US school. Inclusion criteria for the families were that they self-identified as Latinx and had family incomes below $200 \%$ of the federal poverty level. For the rural families, the mother or her cohabitating partner had to be employed in farm work on non-organic farms during the past three years. For the urban families, all adults living in the household could not have been employed in an industry with routine exposure to pesticides (e.g., farm work, landscaping, or pest control) in the previous three years. The urban families also could not have lived adjacent to agricultural fields in the previous three years. Families were excluded from the study if their child had a life-threatening illness, prior history of neurological conditions, physical condition, or development disorder that would not allow them to complete or would interfere with the results of neurobehavioral tests or brain imaging (used in the main study). Families were also excluded if a primary language other than Spanish or English was spoken in the home or the mother refused to complete the questionnaires.

Participants were recruited over the period March 2018 to December 2019. Participants provided data at baseline and at quarterly follow-ups. Eight quarterly follow-ups were planned to be completed over 2 years, but the followup schedule was extended due to interruptions caused by the COVID-19 pandemic. Rural families were recruited in eastern North Carolina counties with large farmworker populations. Urban families were recruited in central North Carolina from Winston-Salem and the surrounding urban counties. For both samples, bilingual research staff contacted parents and explained the overall study procedures, answered questions, and, if the parent agreed to participate, obtained signed informed consent from the parent and assent from the child. The sample for this analysis includes 118 mothers (66 women in rural farmworker families and 52 women in urban non-farmworker families) who completed the CES-D scale in the first quarterly follow-up (completed between July 2019 and March 2020, before data collection was suspended due to the pandemic). Because interviewers worked through community partners, the number of potential participants or their parents who refused to participate is not known.

\section{Data}

Data include those collected in a baseline life history calendar [27] and questionnaire, and in the first quarterly followup questionnaire. The calendar and questionnaires were interviewer administered. A parent, usually the mother, completed the calendar and the two questionnaires. The life history calendars collected information on participants' environmental exposures from conception to date of the interview using an open-ended format [27]. The baseline questionnaire included items about the child's and family's demographic and background characteristics. The follow-up questionnaire included the 10-item, short-form version of the CES-D [19]. Spanish-language items and scales were adapted from existing questionnaires when available. New items were developed in English, translated into Spanish by a native Spanish speaker, and back translated into English by a native English speaker.

Interviewers were native Spanish speakers; all spoke English, but with varying degrees of proficiency. They completed training before data collection began. The interviewers entered data in real time during the interviews using Research Electronic Data Capture (REDCap), hosted at Wake Forest School of Medicine through the Clinical and Translational Science Institute. The REDCap system provides secure, web-based applications for a variety of types of research [28]. Participants were given a \$20 cash incentive for completing the baseline questionnaire and calendar and a \$20 cash incentive for completing the quarterly follow-up questionnaire.

\section{Measures}

Depressive symptoms are measured with a validated Spanish version of the CES-D Short Form (CES-D-10) [19, 29]. Participants rank 10 experiences for the past week on a 4-point scale of zero (rarely or none of the time) to three (most or all of the time). Scores can range from zero to 30 . The scale's Cronbach's alpha for this study is 0.84 . In addition to their total score, participants are also placed into two categories: those with a score of 10 or higher are considered to have elevated depressive symptoms and those with a score lower than 10 do not have elevated depressive symptoms [30].

Independent variables include measures of personal, immigration and acculturation, family composition and disruption, and financial characteristics. Personal characteristic measures are locality in the categories of rural farmworker and urban non-farmworker and age in the categories of 21-29 years, 30-34 years, 35-39 years, and 40-45 years. Immigration and acculturation measures are place of birth in the categories Mexico, other Latin America (including Guatemala, Honduras, El Salvador, Dominican Republic, Venezuela), and the USA (including Puerto Rico); fluent in English (dichotomous); and educational attainment in the categories 11 or fewer years versus 12 or more years.

Marital status is the first measure of family composition and disruption; it has the values of married or living as married versus not currently married. Spouse always present in the household is dichotomous. Number of adults in the household has the values of one, two, and three or more. Number of children in the household has the values of one or two, three, and four or more. Whether the family had 
experienced a deportation is dichotomous. Number of residential moves in the last 8 years has the values of none, one, two, and three or more.

Among financial status measures, occupation is in the dichotomous categories does not work outside the home and employed outside the home; among those employed outside the home, the number working in major occupation groups are reported. Occupational groups include farm work, production operative (assembly line manufacturing worker), cleaning and maintenance, and other. Food security in the categories of high versus other (marginal, low, very low) is measured with the Spanish-language adaptation [31] of the US Household Food Security Survey Module [32]. Financial hardship in the past 8 years in the categories often, rarely, and never is measured with an item from an adverse childhood experiences inventory [33].

\section{Statistical Analysis}

Descriptive statistics (counts, percentages or median, 25th-75th percentile as appropriate) were calculated overall and by farmworker status for the participant characteristics of interest as well as the depressive symptom scores. Associations between these variables and farmworker status were tested using Chi-Square, Fisher's Exact, or Kruskal-Wallis tests as appropriate.

The depressive symptom score was highly skewed in this sample. Therefore, it was further summarized within participant characteristics by calculating the median (25th-75th percentile), and Kruskal-Wallis tests were used for bivariate associations. Finally, to examine the relationship between median depressive symptom scores and selected measures from personal, immigration and acculturation, family composition and disruption, and financial characteristics, a multivariable model was created. Covariates for the model were selected based on the lowest $p$ value within a category from the bivariate associations, and a multivariate quantile linear regression for median was employed where standard errors were found from resampling with 5000 bootstrap replications. $p$ values less than 0.05 were considered statistically significant.

\section{Results}

\section{Personal Characteristics}

The women were aged 24 through 45 years, with most aged $30-34$ years $(31.4 \%)$ and 35-39 years $(28.8 \%)$ (Table 1$)$. Most were born in Mexico (78.0\%). Fewer than one-in-five were fluent in English, with significantly fewer rural (10.6\%) than urban (28.8\%) women being fluent English speakers. About one quarter had 12 or more years of education, with significantly fewer rural (18.2\%) than urban $(38.5 \%)$ women having completed high school. Most were married (85.6\%), with their spouse always being present (77.9\%). The rural and urban women were similar in the number of adults and children in their households, with most (74.6\%) living in households with two adults. Few of the women had experienced a deportation in their family. About one quarter of the women had experienced 3 or more residential moves, with this percent being significantly lower among rural (14.1\%) than urban (42.9\%) women. About one third (30.5\%) stated that they did not work outside the home, with this percent being greater for urban (48.1\%) compared to rural (16.7\%) women. The employed women worked largely in the manual occupations farm work, production operative, and cleaning and maintenance. A plurality (40.7\%) reported high food security; however, among those who did not report high food security, $39.0 \%$ reported low and 3.4\% reported very low food security. One third reported often having a financial hardship.

\section{Depressive Symptoms}

The CES-D scores were highly skewed with 27 (22.9\%) zeros. The mean (SD) was 3.5 (4.4). The median depressive symptom score reported was $2.0(1.0-4.0)$, with $10(8.5 \%)$ women having depressive symptom scores of 10 or greater (Table 2). The rural and urban women did not significantly differ in median depressive symptom scores or the number with scores of 10 or greater.

The women did not significantly differ in depressive symptom scores by age (Table 3 ). The women did significantly differ in depressive symptom scores in terms of several immigration and acculturation characteristics. Women born in the USA had lower median scores (0.5) than did those born in Mexico (2.0) or in other Latin American countries (3.0). Those who spoke English fluently had lower scores than those who did not (1.5 versus 2.0$)$. Women differed in depressive symptom scores in terms of several family composition and disruption characteristics. Married women had significantly lower scores than did those who were not currently married (2.0 versus 4.0 ). Women living in households with only two adults had significantly lower scores (2.0) than did those living in households with one adult (5.0) or more than two adults (4.0). Those women reporting that a spouse was always present in the family reported lower scores than did those indicating a spouse was not always present (2.0 versus 3.0), and those not experiencing a deportation in the family reported lower scores those who did (2.0 versus 4.0). These last two associations only approached statistical significance. None of the financial status characteristics had statistically significant associations with the depressive symptom scores.

The multivariate analysis of depressive symptom scores included locality (rural farmworker versus urban 
Table 1 Participant personal, immigration and acculturation, family composition and disruption, and financial characteristics for Latinx women in rural farmworker and urban non-farmworker families, North Carolina, 2018-2019

\begin{tabular}{llll}
\hline Participant personal, immigration and acculturation, family & All participants & Rural farmworker & Urban non-farm- $p$ \\
composition and disruption, and financial characteristics & $n=118$ & $n=66$ & worker \\
& $\mathrm{n}(\%)$ & $\mathrm{n}(\%)$ & $\mathrm{n}(\%)$ \\
& & & $\mathrm{n}(\%)$ \\
\hline
\end{tabular}

\section{Personal}

Age (in years)

$30-34$

$23(19.5)$

37 (31.4)

$34(28.8)$

35-39

$24(20.3)$

\section{migration and acculturation}

Place of Birth

Mexico

Other Latin America

USA

Fluent in English

No

Yes

Educational attainment

11 years or fewer years

12 or more years

\section{Family composition and disruption}

Marital status

Married/living as married

Not married

Spouse always present in family ${ }^{1}$

No

Yes

$92(78.0)$

18 (15.2)

$8(6.8)$

$96(81.4)$

22 (18.6)

86(72.9)

32 (27.1)

54 (81.8)

$12(18.2)$

$53(80.3)$

$10(15.2)$

3 (4.5)

59 (89.4)

7 (10.6)

12 (18.2)

27 (40.9)

17 (25.8)

10 (15.2)

0.07

Number of adults in household

1

2

3 or more

Number of children in household ${ }^{2}$

1 or 2

3

4 or more

Deportation in family

No

Yes

Number of residential moves ${ }^{2}$

0

1

2

3 or more

Financial status

Occupation

Does not work outside the home

Employed outside the home

Farm work

Production operative
$101(85.6)$

17 (14.4)

25 (22.1)

88 (77.9)

14 (11.9)

88 (74.6)

16 (13.6)

42 (35.9)

37 (31.6)

38 (32.5)

109 (92.4)

9 (7.6)

27 (23.9)

34 (30.1)

22 (19.5)

30 (26.5)

36 (30.5)

82 (69.5)

31 (26.3)

18 (15.3)
55 (83.3)

11 (16.7)

14 (21.9)

$50(78.1)$

$10(15.2)$

$51(77.3)$

5 (7.6)

23 (34.9)

22 (33.3)

21 (31.8)

62 (93.9)

4 (6.1)

18 (28.1)

26 (40.6)

$11(17.2)$

9 (14.1)

$11(16.7)$

55 (83.3)

31 (47.0)

$10(15.2)$
$<0.01$

25 (48.1)

27 (51.9)

$0(0.0)$

11 (21.2)

$10(19.2)$

17 (32.7)

14 (26.9)

$39(75.0)$

8 (15.4)

5 (9.6)

0.01

37 (71.2)

15 (28.8)

32 (61.5)

20 (38.5)

0.01

0.43

46 (88.5)

$6(11.5)$

$11(22.5)$

38 (77.5)

4 (7.7)

37 (71.2)

11 (21.1)

19 (37.3)

15 (29.4)

17 (33.3)

$47(90.4)$

5 (9.6)

9 (18.4)

8 (16.3)

$11(22.4)$

$21(42.9)$

0.90

0.50

$<0.01$

$8(15.4)$ 
Table 1 (continued)

\begin{tabular}{|c|c|c|c|c|}
\hline $\begin{array}{l}\text { Participant personal, immigration and acculturation, family } \\
\text { composition and disruption, and financial characteristics }\end{array}$ & $\begin{array}{l}\text { All participants } \\
n=118 \\
\mathrm{n}(\%)\end{array}$ & $\begin{array}{l}\text { Rural farmworker } \\
n=66 \\
\mathrm{n}(\%)\end{array}$ & $\begin{array}{l}\text { Urban non-farm- } \\
\text { worker } \\
n=52 \\
\mathrm{n}(\%)\end{array}$ & $p$ \\
\hline Cleaning and Maintenance & $11(9.3)$ & $6(9.1)$ & $5(9.6)$ & \\
\hline Other & $22(18.6)$ & $8(12.1)$ & $14(26.9)$ & \\
\hline Food security & & & & 0.42 \\
\hline High & $48(40.7)$ & $29(43.9)$ & $19(36.5)$ & \\
\hline Other (Marginal, Low, Very low) & $70(59.3)$ & $37(56.1)$ & $33(63.5)$ & \\
\hline Marginal & $20(16.9)$ & $9(13.6)$ & $11(21.2)$ & \\
\hline Low & $46(39.0)$ & $28(42.4)$ & $18(34.6)$ & \\
\hline Very low & $4(3.4)$ & $0(0.0)$ & $4(7.7)$ & \\
\hline Financial hardship & & & & 0.45 \\
\hline Often & $40(33.9)$ & $25(37.9)$ & $15(28.8)$ & \\
\hline Rarely & $56(47.5)$ & $28(42.4)$ & $28(53.9)$ & \\
\hline Never & 22 (18.6) & $13(19.7)$ & $9(17.3)$ & \\
\hline
\end{tabular}

${ }^{1} n=113$

${ }^{2} n=117$

non-farmworker), as well as measures for each of the three sets of factors. The three immigration and acculturation measures were correlated. The one with the smallest $p$ value in the bivariate analysis, fluent in English, was included in the multivariate model. Three significant and near significant family composition and disruption measures, marital status, spouse always present in family, and number of adults in family were correlated. The one with the smallest $p$ value in the bivariate analysis, marital status, was included in the multivariate model. The measure deportation in family was also included in the multivariate model because it had a near significant association in the bivariate analysis. None of the three financial status measure had a significant association with depressive symptom score in the bivariate analysis. The one with the smallest $p$ value, financial hardship, was included in the multivariate model.

Although not having a statistically significant association in the bivariate analysis, locality did have a significant association with depressive symptom score in the multivariate analysis (Table 4). Rural farmworker women had an expected median score one point lower than did urban non-farmworker women. In addition, women not fluent in English had an expected median score one point greater than those fluent in English, although only approaching statistical significance $(p=0.06)$. Similarly, unmarried women had an expected score two points greater than married women, although only approaching statistical significance $(p=0.06)$.

\section{Discussion}

The depressive symptom scores for the Latinx women in farmworker families and in non-farmworker families are low compared to other research [12, 20-23]. Although these scores are low, depressive symptoms were still common among these women, with $8.5 \%$ having sufficient scores to be considered elevated depressive symptoms. This is similar to the $8.1 \%$ of US adults whom meet criteria for depression [34]. Okonji and colleagues [35] conclude that immigrants have lower odds of having depression than do US citizens.
Table 2 Depressive symptom scores for Latinx women in rural farmworker and urban non-farmworker families, North Carolina, 2018-2019

\begin{tabular}{|c|c|c|c|c|}
\hline Depressive symptom scores & $\begin{array}{l}\text { All participants } \\
n=118\end{array}$ & $\begin{array}{l}\text { Rural, farmworker } \\
n=66\end{array}$ & $\begin{array}{l}\text { Urban, non-farmworker } \\
n=52\end{array}$ & $p$ value \\
\hline $\begin{array}{l}\text { Median depressive symptom } \\
\text { scores }(25 \text { th- } 75 \text { th per- } \\
\text { centile) }\end{array}$ & $2.0(1.0-4.0)$ & $2.0(1.0-3.0)$ & $2.5(1.0-6.0)$ & 0.27 \\
\hline $\begin{array}{l}\text { Number }(\%) \text { with a depres- } \\
\text { sive symptom score of } 10 \\
\text { or greater }\end{array}$ & & & & 0.33 \\
\hline Fewer than 10 & $108(91.5)$ & $62(93.9)$ & $46(88.5)$ & \\
\hline 10 or greater & $10(8.5)$ & $4(6.1)$ & $6(11.5)$ & \\
\hline
\end{tabular}


Table 3 Bivariate associations of participant personal, immigration and acculturation, family composition and disruption, and financial characteristics with depressive symptom scores for Latinx women in rural farmworker and urban von-farmworker families, North Carolina, 2018-2019 $(N=118)$
Participant personal, immigration and acculturation, family composition and disruption, and financial characteristics

Median depressive symptom

$p$ value scores

(25th-75th percentile)

\section{Personal characteristics}

Age (in years)

0.28

21-29

$2.0(0.0-3.0)$

30-34

$2.0(1.0-4.0)$

35-39

$2.0(1.0-3.0)$

40-45

$3.0(1.5-6.0)$

Immigration and acculturation

Place of birth

0.02

Mexico

Other Latin America

USA

No

0.10

Educational attainment

$$
11 \text { years or fewer }
$$

12 or more years

$2.0(1.0-4.0)$

$3.0(1.0-6.0)$

$0.5(0.0-2.0)$

$2.0(1.0-5.5)$

$1.5(0.0-2.0)$

$2.0(1.0-5.0)$

$1.5(0.0-3.0)$

Family composition and disruption

Marital status

Married/living as married

Not married

Spouse always present in family ${ }^{1}$

No

Yes

Number of adults In household

2

3 or more

Number of children in household ${ }^{2}$

1 or 2

3

4 or more

Deportation in family

No

Yes

Number of residential moves ${ }^{2}$

0

1

2

3 or more

Financial status

Occupation

Does not work outside the home

Employed outside the home

Food security

High

Other (marginal, low, very low)

Financial hardship

Often

Rarely

Never

${ }^{1} n=113$

${ }^{2} n=117$
$2.0(1.0-6.0)$

$2.0(0.0-3.0)$

$4.0(3.0-7.0)$

$3.0(2.0-7.0)$

$2.0(1.0-3.5)$

$5.0(3.0-8.0)$

$2.0(0.0-3.0)$

$4.0(0.5-5.5)$

$2.0(0.0-5.0)$

$2.0(1.0-3.0)$

$3.0(1.0-5.0)$

$2.0(1.0-4.0)$

$4.0(2.0-7.0)$

$2.0(1.0-5.0)$

$2.0(1.0-3.0)$

$2.0(1.0-3.0)$

$2.5(1.0-7.0)$

$2.0(1.0-3.0)$

$2.0(1.0-3.0)$

$2.0(1.0-5.0)$

$3.0(2.0-5.5)$

$2.0(1.0-5.0)$

$1.0(0.0-3.0)$ 
Table 4 Multivariate associations of participant personal, immigration and acculturation, family composition and disruption, and financial characteristics with depressive symptom scores for Latinx women in rural farmworker and urban non-farmworker families, North Carolina, 2018-2019 $(N=118)$

\begin{tabular}{lllc}
\hline $\begin{array}{l}\text { Participant personal, immigration and acculturation, family } \\
\text { composition and disruption, and financial characteristics }\end{array}$ & Estimate & Standard error & 95\% Confidence limits \\
\hline Rural farmworker vs urban non-farmworker & -1.000 & 0.493 & $-1.977,-0.023$ \\
Not fluent vs fluent in English & 1.000 & 0.543 & $-0.075,2.075$ \\
Not married vs married & 2.000 & 1.057 & $-0.094,4.094$ \\
Deportation vs no deportation in family & 1.000 & 2.029 & $-3.021,5.021$ \\
Financial hardship & & & 0.04 \\
$\quad$ Often vs never & 1.000 & 0.647 & $-0.281,2.281$ \\
$\quad$ Rarely vs never & 1.000 & 0.655 & $-0.299,2.299$ \\
\hline
\end{tabular}

Within the multivariable model, rural-urban locality is associated with the depression score among these women, with rural farmworker women having significantly lower scores than the urban non-farmworker women. More urban non-farmworker than rural farmworker women (11.5\% versus $6.1 \%$ ) also reported elevated depressive symptom scores of 10 or greater. This reflects the one other study [12] comparing rural and urban Latinas, which found that urban women had significantly greater depression scale scores. Latinx children in urban non-farmworker communities also report more adverse childhood experiences than do Latinx children in rural farmworker communities [36]. Locality reflects the complex situation of Latinas in the USA. Latinas living in rural areas, even those subjected to the vulgarities of agricultural work, may obtain some level of mental health protection. Additional research on the components of locality is needed to parcel out the more proximal determinants of depressive symptoms in these communities.

Factors in the two domains immigration and acculturation, and family composition and disruption are associated with depression scores in the bivariate analysis but only marginally so in the multivariate analysis. Being born in the USA is associated with lower depressive symptom scores. Research among immigrant Latinas reports that immigration-related stressors, such as worry about immigration enforcement and broken social ties, are important [37]. Roblyer and colleagues [38] report that documentation status is a stressor among undocumented Latinas, but this stressor is not associated with greater depressive symptoms. Being fluent in English is also associated with lower depressive symptom scores. At the same time, the urban women were more likely to be fluent in English and to have higher depression scores. Research should address whether fluency has different functions or meaning among urban and rural Latinx women. For example, fluency may buffer against stress among rural women, but lead to greater awareness of discrimination, disparities, or fears of deportation among urban women.
The indicators of family composition and disruption, not being married (recall that all of the participants had at least one co-resident child that was 8 years old when recruited to the study) and living in a household with one or with three or more adults (versus two adults), are associated with a greater depressive symptom score among the participants. Family composition is reported to be associated with greater depressive symptom scores [21]. Similarly, lower family cohesion and social support are associated with higher depressive symptom scores [38]. The non-linear association of household size with depressive symptom score (single parent and households with three or more adults are associated with higher depressive symptom scores) suggests that being a single parent and caring for other adults as well as children are stressors.

As found in other analyses, occupation is not associated with depressive symptom scores in this study [12, 20]. Financial stability, as measured by food security and reporting a financial hardship, is not associated with depressive symptom score in this study. This is surprising and contradicts other findings for women in farmworker families [21]. It is also at odds with other research examining the association of financial status in other analyses of low-income populations in the USA [24, 25, 39, 40] and elsewhere [41]. This may be a result of homogeneity across the participants due to the inclusion criteria of having a total household income below $200 \%$ of the federal poverty level.

\section{Limitations and strengths}

Interpreting these results should be tempered by understanding the limitations of this research. The analysis is based on a small, non-random sample. Participants had to be mothers of an 8-year old child, and all were in low-income families (family income below $200 \%$ of federal poverty level). All of these factors limit generalizability. The analysis is crosssectional, when the experience of depressive symptoms is cyclical [23]. The depression scores are low; it is unclear whether they reflect meaningful burden of depression or 
small increments in very low general levels of self-reported symptoms. At the same time, PACE5 is a long-term community-based participatory research project with a history of collaboration with North Carolina Latinx farmworker and non-farmworker communities.

\section{Conclusions}

These results are testimony to the complexity of understanding mental health among immigrant women, particularly immigrant women in farmworker families. Where these immigrants live, in rural versus urban communities, provides a context for mental health. The importance of locality and the proximal determinants of locality require further analysis. Although financial status among these consistently low-income women was not associated with depressive symptom scores, unsurprisingly, acculturation and family composition were important to reporting fewer depressive symptoms. Further analysis of general mental health and depressive symptoms is needed to inform clinical care among Latina. This study is fortunate to have a wide perspective on the complexity of depressive symptoms in this community that will allow an examination of longitudinal data for these women.

Acknowledgements The authors appreciate the support of their community partners, the North Carolina Farmworkers Project and Student Action with Farmworkers, and appreciate the valuable contributions of our community field interviewers in carrying out participant recruitment and data collection. They especially thank the women who participated in this study.

Authors' Contributions TAA, HC, SAQ, and PJL developed the research question and conceptualized the study design. PJL directed data collection. JWT established and maintained the data files. TAA, SAS, HC, and JWT conceptualized the analysis approach and SAS conducted the data analysis. TAA and SAS drafted the manuscript. All authors reviewed and approved the final manuscript version.

Funding The National Institute of Environmental Health Sciences funded this research through grant number R01 ES08739. The content is solely the responsibility of the authors and does not necessarily represent the official views of the National Institutes of Health.

Availability of Data and Material Due to the nature of this research, participants of this study did not agree for their data to be shared publicly, so supporting data are not available.

Code Availability Not applicable.

\section{Declarations}

Ethics The Wake Forest School of Medicine Institutional Review Board approved the study protocol 9IRB00043066).

Consent to Participate Adult participants gave signed informed consent; child participants in the larger study gave signed assent.
Consent for Publication Not applicable.

Conflict of Interest The authors declare no competing interests.

\section{References}

1. Hsieh YC, Apostolopoulos Y, Hatzudis K, Sönmez S. Social, occupational, and spatial exposures and mental health disparities of working-class Latinas in the US. J Immigr Minor Health. 2016;18:589-99. https://doi.org/10.1007/s10903-015-0231-z.

2. Furgurson KF, Quandt SA. Stress and distress: Mental health among Latinx farmworkers in the Eastern United States. Pp. 83-105. Arcury TA, Quandt SA, eds. Latinx Farmworkers in the Eastern United States: Health, Safety, and Justice ( $2^{\text {nd }}$ edition). New York: Springer; 2020.

3. Murphy J, Samples J, Morales M, Shadbeh N. "They talk like that, but we keep working": Sexual harassment and sexual assault experiences among Mexican indigenous farmworker women in Oregon. J Immigr Minor Health. 2015;17(6):1834-9. https://doi.org/10.1007/s10903-014-9992-z.

4. Prado KY, Rivera-Heredia ME, Martínez-Servín LG, GuzmánCarillo KY, McCurdy SA. "It's wrong because it could be my sister, wife, or mother": Workplace sexual harassment among men and women farmworkers in USA and Mexico. J Agromedicine. 2021;26:220-30. https://doi.org/10.1080/1059924X.2020. 1825245.

5. Kim NJ, Vásquez VB, Torres E, Nicola RM, Karr C. Breaking the silence: Sexual harassment of Mexican women farmworkers. J Agromedicine. 2016;21(2):154-62. https://doi.org/10.1080/ 1059924X.2016.1143903.

6. Hovey JD, Magaña C. Acculturative stress, anxiety, and depression among Mexican immigrant farmworkers in the Midwest United States. J Immigr Health. 2000;2:119-31. https://doi.org/ 10.1023/A:1009556802759.

7. Ramos AK, Su D, Lander L, Rivera R. Stress factors contributing to depression among Latino migrant farmworkers in Nebraska. J Immigr Minor Health. 2015;17:1627-34. https:// doi.org/10.1007/s10903-015-0201-5.

8. Smith MN, Wilder CS, Griffith WC, Workman T, Thompson B, Dills R, Onstad G, Vredevoogd M, Vigoren EM, Faustman EM. Seasonal variation in cortisol biomarkers in Hispanic mothers living in an agricultural region. Biomarkers. 2015;20:299-305. https://doi.org/10.3109/1354750X.2015.1068863.

9. Cherry DJ, Rost K. Alcohol use, comorbidities, and receptivity to treatment in Hispanic farmworkers in primary care. J Health Care Poor Underserved. 2009;20:1095-110. https://doi.org/10. 1353/hpu.0.0215.

10. Boggess B, Bogue HO. The health of U.S. agricultural worker families: A descriptive study of over 790,000 migratory and seasonal agricultural workers and dependents. J Health Care Poor Underserved. 2016;27:778-92. https://doi.org/10.1353/ hpu.2016.0089.

11. Arcury TA, Talton JW, Summers P, Chen H, Laurienti PJ, Quandt SA. Alcohol consumption and risk for dependence among male Latino migrant farmworkers compared to Latino nonfarmworkers in North Carolina. Alcohol Clin Exp Res. 2016;40:377-84. https://doi.org/10.1111/acer.12969.

12. Arcury TA, Sandberg JC, Talton JB, Laurienti PJ, Daniel SS, Quandt SA. Mental health among Latina farmworkers and other employed Latinas in North Carolina. Rural Ment Health. 2018;42:89-101. https://doi.org/10.1037/rmh0000091. 
13. Sánchez J. Alcohol use among Latino migrant workers in South Florida. Drug Alcohol Depend. 2015;151:241-9. https://doi.org/ 10.1016/j.drugalcdep.2015.03.025.

14. Chaney BH, Torres E. Covariates of Identified Stress and Depression among Seasonal Farmworkers. Int J Environ Res Public Health. 2017;14:711. https://doi.org/10.3390/ijerph14070711.

15. Georges A, Alterman T, Gabbard S, Grzywacz JG, Shen R, Nakamoto J, Carroll DJ, Muntaner C. Depression, social factors, and farmworker health care utilization. J Rural Health. 2013;29(Suppl 1):s7-16. https://doi.org/10.1111/jrh.12008.

16. Kim-Godwin YS, Maume MO, Fox JA. Depression, stress, and intimate partner violence among Latino migrant and seasonal farmworkers in rural Southeastern North Carolina. J Immigr Minor Health. 2014;16:1217-24. https://doi.org/10.1007/ s10903-014-0007-x.

17. Nguyen HT, Quandt SA, Grzywacz JG, Chen H, Galván L, KitnerTriolo MH, Arcury TA. Stress and cognitive function in Latino farmworkers. Am J Ind Med. 2012;55:707-13. https://doi.org/10. 1002/ajim.22035.

18. Quandt SA, Kinzer HT, Trejo G, Mora DC, Sandberg JC. The health of women farmworkers and women in farmworker families in the Eastern United States. Pp. 133-161. Arcury TA, Quandt SA, eds. Latinx Farmworkers in the Eastern United States: Health, Safety, and Justice ( $2^{\text {nd }}$ edition). New York: Springer; 2020.

19. Grzywacz JG, Hovey JD, Seligman LD, Arcury TA, Quandt SA. Hisp J Behav Sci. 2006;28:404-24.

20. Arcury TA, Trejo G, Suerken CK, Grzywacz JG, Ip EH, Quandt SA. Work and health among Latina mothers in farmworker families. J Occup Environ Med. 2015;57:292-9. https://doi.org/10. 1097/JOM.0000000000000351.

21. Roblyer MI, Grzywacz JG, Suerken CK, Trejo G, Ip EH, Arcury TA, Quandt SA. Interpersonal and social correlates of depressive symptoms among Latinas in farmworker families living in North Carolina. Women Health. 2016;56:177-93. https://doi.org/10. 1080/03630242.2015.1086464

22. Pulgar CA, Trejo G, Suerken C, Ip EH, Arcury TA, Quandt SA. Economic hardship and depression among women in Latino farmworker families. J Immigr Minor Health. 2016;18:497-504. https://doi.org/10.1007/s10903-015-0229-6.

23. Marshall SA, Ip EH, Suerken CK, Arcury TA, Saldana S, Daniel SS, Quandt SA. Relationship between maternal depression symptoms and child weight outcomes in Latino farmworker families. Matern Child Nut. 2018;4:e12614. https://doi.org/10.1111/mcn. 12614.

24. Belle D, Doucet J. Poverty, inequality and discrimination as sources of depression among U.S. women. Psychol Women Q. 2003;27:101-13. https://doi.org/10.1111/1471-6402.00090.

25. Eamon MK, Zuehl RM. Maternal depression and physical punishment as mediators of the effect of poverty on socioemotional problems of children in single-mother families. Am J Orthopsychiatry. 2001;71:218-26. https://doi.org/10.1037/0002-9432.71.2.218.

26. Arcury TA, Grzywacz JG, Chen H, Mora DC, Quandt SA. Work organization and health among immigrant women: Latina manual workers in North Carolina. Am J Public Health. 2014;104:244552. https://doi.org/10.2105/AJPH.2013.301587.

27. Quandt SA, Mora DC, Seering TL, Chen H, Arcury TA, Laurienti PJ. Using life history calendars to estimate in utero and early life pesticide exposure of Latinx children in farmworker families. Int J Environ Res Public Health. 2020;17:E3478. https://doi.org/10. 3390/ijerph17103478.

28. Harris PA, Taylor R, Thielke R, Payne J, Gonzalez N, Conde JG. Research electronic data capture (REDCap) - A metadata-driven methodology and workflow process for providing translational informatics support. J Biomed Inform. 2009;42:377-81. https:// doi.org/10.1016/j.jbi.2008.08.010.
29. Kohout FJ, Berkman LF, Evans DA, Cornoni-Huntley J. Two shorter forms of the CES-D (Center for Epidemiological Studies Depression) depression symptoms index. J Aging Health. 1993;5:179-93. https://doi.org/10.1177/089826439300500202.

30. Andresen EM, Malmgren JA, Carter WB, Patrick DL. Screening for depression in well older adults: evaluation of a short form of the CES-D (Center for Epidemiologic Studies Depression Scale). Am J Prev Med. 1994;10:77-84.

31. Harrison GG, Stormer A, Herman DR, et al. Development of a Spanish-language version of the US Household Food Security Survey module. J Nutr. 2003;133:1192-7.

32. Bickel G, Nord M, Price C, et al. Guide to Measuring Household Food Security: Revised 2000. U.S. Department of Agriculture, Food and Nutrition Service, Office of Analysis, Nutrition, and Evaluation; Washington, DC; 2000.

33. Loria H, Caughy M. Prevalence of adverse childhood experiences in low-income Latino immigrant and nonimmigrant children. J Pediatrics. 2018;192:209-15.e1. https://doi.org/10.1016/j.jpeds. 2017.09.056.

34. Brody DJ, Pratt LA, Hughes JP. Prevalence of depression among adults aged 20 and over: United States, 2013-2016. NCHS Data Brief, no 303, 2018. https://www.cdc.gov/nchs/products/datab riefs/db303.htm. Accessed 9 Aug 2021.

35. Okonji AI, Inungu JN, Akinmoladun TM, Kushion ML, AdusePoku L. Factors associated with depression among immigrants in the U.S. J Immigr Minor Health. 2021;23:415-24. https://doi.org/ 10.1007/s10903-021-01141-7.

36. Dobbins DL, Berenson LM, Chen H, Quandt SA, Laurienti PJ, Arcury TA. Adverse childhood experiences among low-income Latinx children: Comparison of children in rural farmworker and urban non-farmworker communities. J Immigr Minor Health. 2021. https://doi.org/10.1007/s10903-021-01274-9.

37. Rios Casas F, Ryan D, Perez G, Maurer S, Tran AN, Rao D, Ornelas IJ. "Se vale llorar y se vale reír": Latina immigrants' coping strategies for maintaining mental health in the face of immigration-related stressors. J Racial Ethn Health Disparities. 2020;7:937-48. https://doi.org/10.1007/s40615-020-00717-7.

38. Roblyer MIZ, Carlos FL, Merten MJ, Gallus K, Grzywacz JG. Psychosocial factors associated with depressive symptoms among Latina immigrants living in a new arrival community. J Latina-O Psychol. 2017;2:103-17. https://doi.org/10.1037/lat0000068.

39. Palar K, Frongillo EA, Escobar J, Sheira LA, Wilson TE, Adedimeji A, Merenstein D, Cohen MH, Wentz EL, Adimora AA, Ofotokun I, Metsch L, Tien PC, Turan JM, Weiser SD. Food insecurity, internalized stigma, and depressive symptoms among women living with HIV in the United States. AIDS Behav. 2018;22:386978. https://doi.org/10.1007/s10461-018-2164-8.

40. Bowie SL, Banks S, Dopwell DM, Martin KB. A differential analysis of depressed mood symptomology among welfare-reliant African American and Latinx women heads of household. J Poverty. 2021. https://doi.org/10.1080/10875549.2021.1929659.

41. van der Waerden JE, Hoefnagels C, Hosman CM, Jansen MW. Defining subgroups of low socioeconomic status women at risk for depressive symptoms: The importance of perceived stress and cumulative risks. Int J Soc Psychiatry. 2014;60:772-82. https:// doi.org/10.1177/0020764014522751.

Publisher's Note Springer Nature remains neutral with regard to jurisdictional claims in published maps and institutional affiliations. 